\title{
Implementation of SCA Optimized 2-DOF-PID Controller for Standalone PV System

\author{
${ }^{* 1}$ Raj Kumar Sahu, ${ }^{2}$ Binod Shaw \\ 1,2 National Intitute of Technology, Raipur, India. \\ Email: rajkumarsao@gmail.com,binodshaw2000@gmail.com
}

Received: 20th November 2019, Accepted: 31st January 2020, Published: 29th February 2020

\begin{abstract}
Maximum Power Point Tracking (MPPT) helps to reduce the oscillation around maximum power point (MPP) and enhances the efficiency of the Photovoltaic (PV) system. Two Degree of Freedom PID (2-DOFPID) based MPPT controller is implemented to generate adequate gate pulse for DC-DC converter. Sine Cosine Algorithm (SCA) is a new optimization technique, which is adopted to elect the relevant best values of the gain parameters of both 2-DOF-PID and PID controllers for better the performance. The performance of proposed controller is validated with the Fuzzy logic controller (FLC), Proportional Integral Derivative controller (PID) and Perturb \& Observation (P\& O).
\end{abstract}

\section{Keywords}

Two Degree of Freedom PID (2-DOF-PID), Fuzzy logic Controller (FLC), Maximum Power Point Tracking $(M P P T)$, Perturb and Observe $(P \& O)$, Proportional-Integral-Derivative (PID) controller, Sine Cosine Algorithm (SCA).

\section{Introduction}

A large portion of the power production is from a traditional energy source such as fossil fuel, nuclear, etc. The demand for electricity is exponential rising. Due to the rise in population, the decrease in the stock of non-renewable resources and increasing commercial, sustainable power sources adds to fulfil the need. Sunpowered $\mathrm{PV}$ is one of the most basic methodologies among sustainable power sources. The explanation behind the PV system leads among all the renewable energy sources is pollution-free, noise-free, long life and low maintenance. The performance of the PV system is directly proportional to the photon energy of the sun or the irradiation of the sun. Irradiation and temperature affect the performance of the PV system and its work as nonlinear. MPPT is a technique to continuously follow the MPP. It improves the performance of the PV system under variable atmospheric conditions. Since the last two decades, many MPPT techniques are implemented to extract maximum power and presently also work on enhancing the performance of the PV system. Many MPPT techniques [1] have implemented and compared the performance of 19 MPPT methods. The $\mathrm{P} \& \mathrm{O}$ technique is an old technique and most widely used due easy to its implementation. [2[[3] Adaptive step size is a modified P \& O technique which enhanced the performance of PV system and validated conventional P \& O technique [4] and variable step size has presented in [5] and the step size is optimized by self-tuning and validated with the conventional method. A brief survey of the application of soft computing techniques for MPPT of PV system under the variable atmospheric condition in [6][7][8][9].The performance of the PV system under variable condition is improved by using the fuzzy logic controller (FLC) is validated with the most widely used P \& O technique. [10] An artificial neural networkbased MPPT technique is applied in the PV system. [11] Optimization techniques have improved the performance of the PV system. [12] Many soft computing and optimization algorithms are implemented to improve efficiency of MPPT of P V system. [13][14][15][16][17][18] In this paper, SCA optimized 2-DOF PID controller is implemented as MPPT is the endeavour to authenticate the above P \& O and PID based MPPT technique to improve the efficiency with the proper duty (D) cycle of the DC-DC boost converter. The above-proposed PV system is implemented in MATLAB/SIMULINK environment.

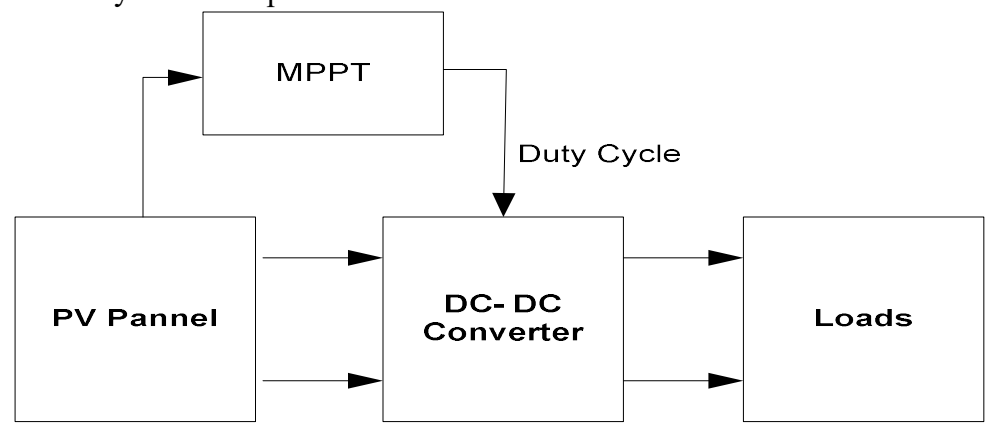

Fig. 1: Block Diagram of Standalone PV System. 


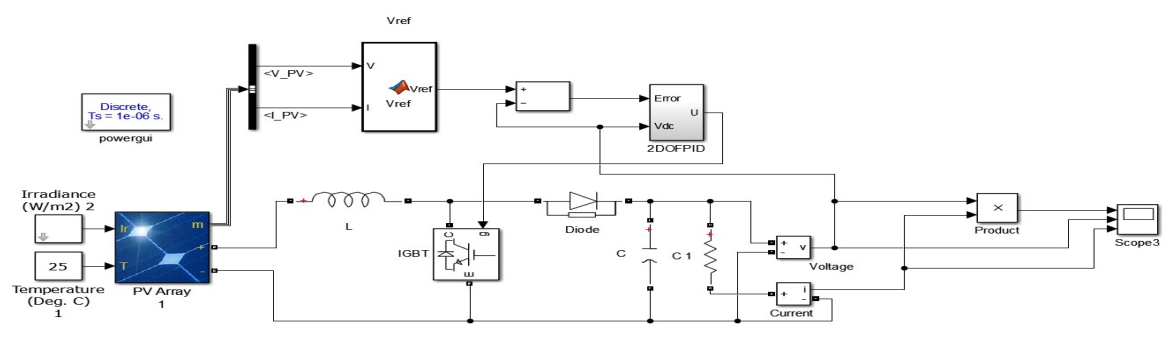

Fig. 2: Simulink Model of Standalone PV System with 2-DOF PID Controller.

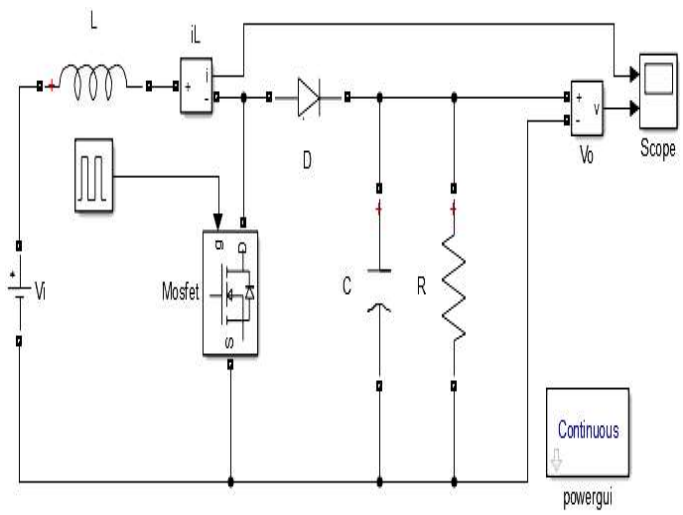

(a)

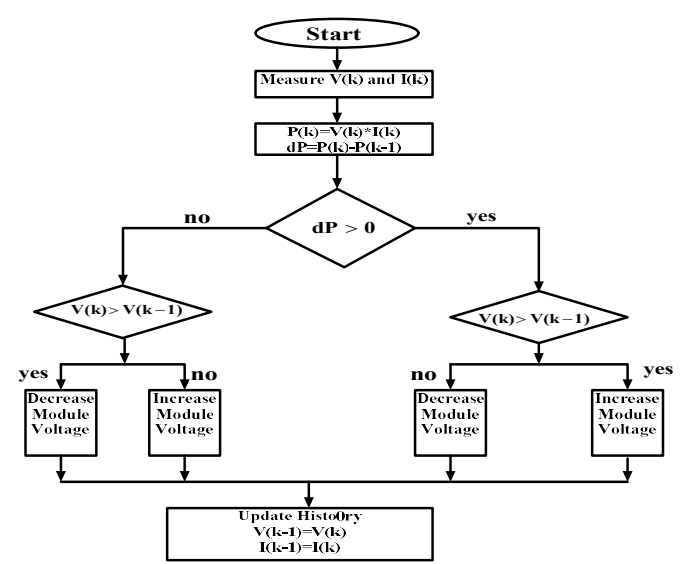

(b)

Fig. 3: (a) Boost Converter and (b) P \& $\mathbf{O}$ Algorithm based $V_{r e f}$ Calculation.

PV System Analysis

The 2-DOF-PID based MPPT controller of standalone PV system's block diagram and Simulink model are depicted in Fig. 1. and Fig. 2. respectively. The proposed model consists of a PV array, DC-DC boost converter, an MPPT controller. MPPT is generating a duty (D) cycle to control the switching action of the DC-DC boost converter. Controlled duty pulse is increases the performance of the proposed PV system.

PV Module

Generally, the PV cell can be explained with the help of equations (1)-(4).

$I_{r r}=I_{s c r} e^{\left(q V_{o c} / K N_{s} A T_{r k}\right)-1}$

$I_{d}=I_{r r}\left(T_{a k} / T_{r k}\right)^{3} e^{\left[\left(E_{g} K / K A\right)\left(1 / T_{r k}-1 / T_{a k}\right)\right]}$

$I_{P H}=I_{s c r}+\left(K_{i}\left(T_{a k}-T_{r k}\right)\right) S / 1000$

$I_{o}=N_{p} I_{P H}-N_{p} I_{d}\left\{e^{\left.\left(q / N_{s} A K T_{a k}\right)\left(V_{o}+I_{o} R_{s}\right)\right]}-1\right\}$

Where $\mathrm{I}_{\mathrm{o}}=\mathrm{PV}$ module current, $\mathrm{V}_{\mathrm{o}}=\mathrm{PV}$ module voltage, $\mathrm{T}_{\mathrm{rk}}=$ Reference temperature in Kelvin, $\mathrm{T}_{\mathrm{ak}}=$ Operating temperature in Kelvin, $\mathrm{S}=$ Irradiance $\mathrm{W} / \mathrm{m}^{2}, \mathrm{q}=$ Charge of electron, $1.6 \times 10^{-19} \mathrm{C}, \mathrm{A}=$ Ideality factor, $\mathrm{K}=$ Boltzman constant, $E_{g}=$ Band Gap, $\mathrm{I}_{\mathrm{scr}}=\mathrm{S} . \mathrm{C}$ current, $\mathrm{N}_{\mathrm{s}}=$ Cells connected in series, $\mathrm{N}_{\mathrm{p}}=$ Cells connected in parallel, $\mathrm{K}_{\mathrm{i}}=\mathrm{S}$.C temperature co-efficient, $\mathrm{R}_{\mathrm{s}}=$ Series Resistance, $\mathrm{I}_{\mathrm{Ph}}=$ Light generated current, DC-DC boost converter. The output voltage of a single PV module is very low for any use. According to the requirement of voltage and current are connected in series and parallel respectively. To obtain the fixed voltage at the output and enhanced the output voltage, a DC-DC boost is implemented. The output voltage is enhanced only by a suitable duty cycle of the converter. Pulse Width Modulation (PWM) technique is used to generate the duty cycle. The proposed standalone PV system model is depicted in Fig.1, and the DC-DC boost converter diagram is depicted in Fig. 3 (a). The mathematical equation of the output voltage and the duty cycle is presented in equation (5) and (6). Time operations like on-off time of the switch are conveyed in equations (7) and (8) respectively by admitting switching period $\left(\mathrm{T}_{\mathrm{s}}\right)$. The specification of the DC-DC boost converter are Inductor (L), Capacitance (C), Load (R) and switching frequency are 100mH, $3000 \mu \mathrm{F}, 5 \Omega$ and $10000 \mathrm{~Hz}$ respectively.

$V_{\text {out }}=\frac{1}{1-D} V_{\text {in }}$
$D=\frac{t_{\text {on }}}{t_{\text {on }}+t_{\text {off }}}$ 
$t_{\text {on }}=D T_{s}$

$t_{\text {off }}=(1-D) T_{s}$

2-DOF-PID Controller Structure

MPPT is used to track the MPP of I-V and P-V curve of PV module. In this paper, a reference voltage $V_{r e f}$ is obtained by correlate the power $P(k)$ with $P(k-1)$ using $\mathrm{P} \& \mathrm{O}$ algorithm is depicted in Fig. 3 (b). The error (e) signal is obtained by differencing of the reference voltage $V_{\text {ref }}$ and Boost converter output terminal voltage. The output of the 2-DOF-PID controller follows the PWM and fed to the switch to improve the performance of the proposed PV system.

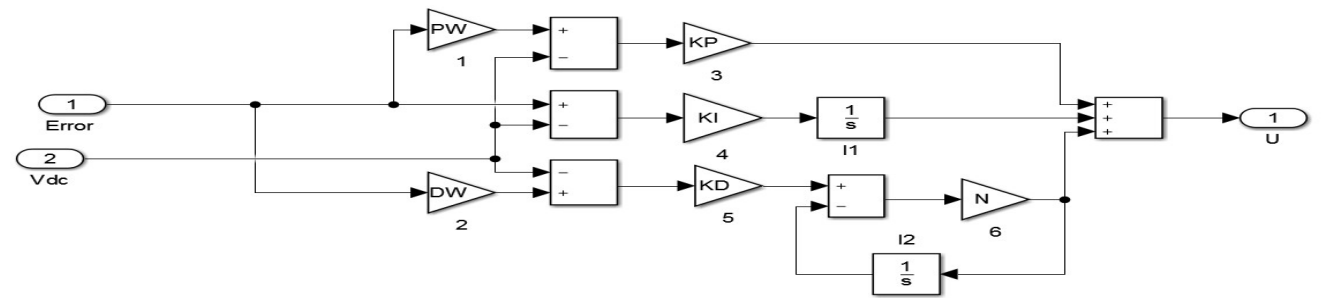

Fig. 4: Structure of 2-DOF-PID Controller.

The 2-DOF-PID controller structure is portrayed in Fig. 4. where 'e' indicates the error signal, ' $V_{d c}$ 'represented the output of DC-DC boost converter and ' $U$ ' shows the output of the controller. The internal structure of the controller has a total six gain parameter are $\mathrm{K}_{\mathrm{P}}, \mathrm{K}_{\mathrm{I}}, \mathrm{K}_{\mathrm{D}}, \mathrm{N}, \mathrm{PW}$ and $\mathrm{DW}$ are proportional, Integral, derivative, derivative filter coefficient, Proportional set point weight and derivative set point weight respectively.[19] To minimize the error of voltage, it's taking the error as reference point. The 2-DOD-PID controller has the beauty to reduce the referral error, author have opted DC output voltage as $\mathrm{V}_{\mathrm{dc}}$. The mathematical equation of the 2DOF PID controller has shown in equation (9) and (10).

$$
\begin{aligned}
& F(S)=\frac{\left(P W K_{P}+D W K_{D}\right) S^{2}+\left(P W K_{P} N+K_{I}\right) S+K_{I} N}{\left(K_{P}+K_{D} N\right) S^{2}+\left(K_{P} N+K_{I}\right) S+K_{I} N} \\
& C(S)=\frac{\left(K_{P}+K_{D} N\right) S^{2}+\left(K_{P} N+K_{I}\right) S+K_{I} N}{S(S+N)}
\end{aligned}
$$

\section{Sine Cosine Algorithm (SCA)}

In this paper, the PID, FLC and 2-DOF PID based MPPT controller structures are planned to add the suitable duty cycle of the converter. The designed parameters of the controllers influence the performance of the system. In this work, a new optimization technique recommended [20] is applied to adjust the gain of the controllers. SCA considers the arbitrary population solution and reasons them to fluctuate nearby the optimal solution. The mathematical equation of SCA is proven by using sine and cosine functions. Many arbitrary values are involved to maintain the exploration and exploitation of search space. The steps involve for SCA are defined as:

1. Set the population matrix of size $[\mathrm{N} \times \mathrm{P}]$, i.e. $[Z]_{N \times P}$. Where $\mathrm{N}$ and $\mathrm{P}$ are the total population and gain factor. For this subject, the definite value of the planned variables is of 0.01 to 2 .

2. Calculate the fitness for all populations to conclude the endpoint for that repetition, i.e. $E_{i}$.

3. The location of the population is modified by with the equation (11) and (12). If $r_{4}<5$

$$
\begin{aligned}
& x_{i}^{t+1}=x_{i}^{t}+r_{1} \times \sin \left(r_{2}\right) \times\left|r_{3} E_{i}^{t}-X_{i}^{t}\right| \quad \text { Otherwise, } \\
& x_{i}^{t+1}=x_{i}^{t}+r_{1} \times \cos \left(r_{2}\right) \times\left|r_{3} E_{i}^{t}-X_{i}^{t}\right|
\end{aligned}
$$

Where $r_{1}$ the decomposing is function and may expressed as; $r_{1}=a-(a \times i) /$ iter $\max$, Where ' $\mathrm{a}$ ' is a constant and $\mathrm{i}$ is the current iteration. $r_{2}$ is the random value between specific limit of 0 to $2 \pi$ and $\mathrm{r} 3$ is the random number between 0 to 1 .

4. Update the $\mathrm{X}$ matrix by comparing the fitness value. The better fitness population will exist for next generation.

5. Repeat the steps from 2 to 4 upto the conclusion benchmarks reach. In this method the maximum iteration is adopted as conclusion benchmarks.

In this work, SCA algorithm is used to obtained optimal gains of PID and 2DOF PID controllers to boost the output response of the PV module. 


\begin{tabular}{|c|c|c|c|c|c|c|}
\hline MPPT Techniques & $\mathrm{K}_{\mathrm{P}}$ & $\mathrm{K}_{\mathrm{I}}$ & $\mathrm{K}_{\mathrm{D}}$ & $\mathrm{PW}$ & $\mathrm{DW}$ & $\mathrm{N}$ \\
\hline PID & 0.0010 & 0.0012 & 0.0010 & & & \\
\hline 2-DOF PID & 1.0124 & 1.3985 & 1.7819 & 3.7566 & 1.2762 & 288.1945 \\
\hline
\end{tabular}

Table 1: Optimal Values of PID and 2-DOF PID Controller.

\begin{tabular}{|c|c|c|c|}
\hline \multirow{2}{*}{$\begin{array}{c}\text { MPPT } \\
\text { Techniques }\end{array}$} & \multicolumn{3}{|c|}{ Maximum Output Response } \\
\cline { 2 - 4 } & Voltage (V) & Current A) & Power (W) \\
\hline 2-DOF PID & 30.34 & 6.07 & 184.1 \\
\hline FLC & 29.87 & 5.97 & 178.6 \\
\hline PID & 18.29 & 3.65 & 66.94 \\
\hline P\&O & 12.43 & 2.45 & 30.7 \\
\hline
\end{tabular}

Table 2: Performance of Boost Converter.

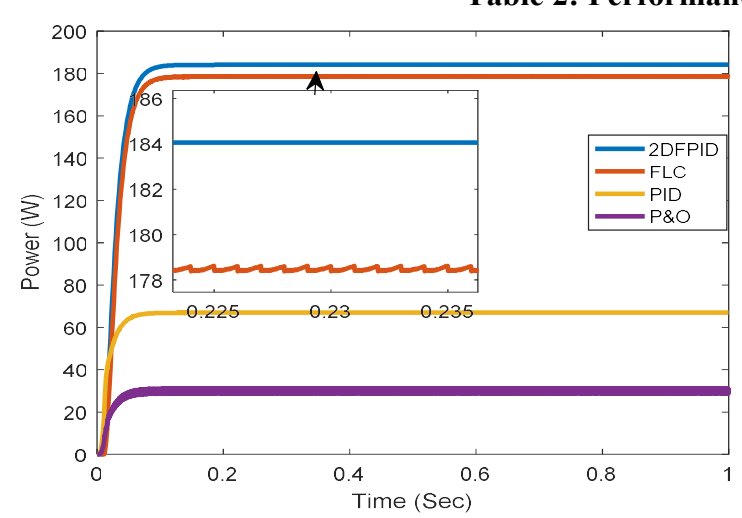

(a)

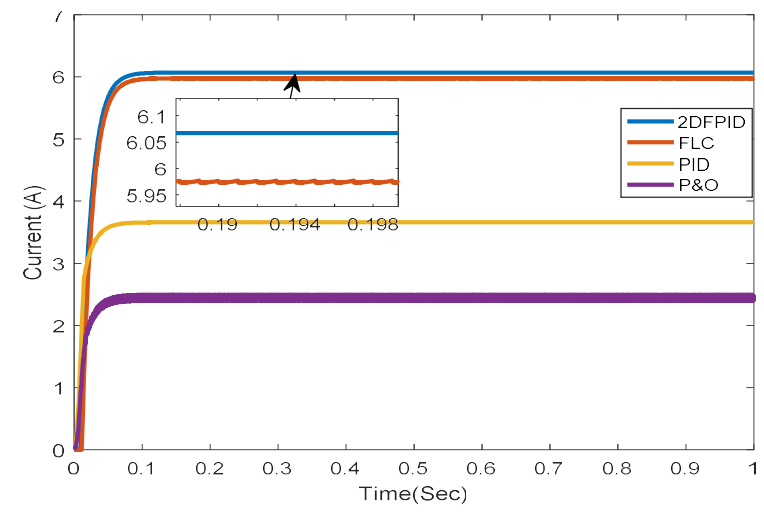

(c)

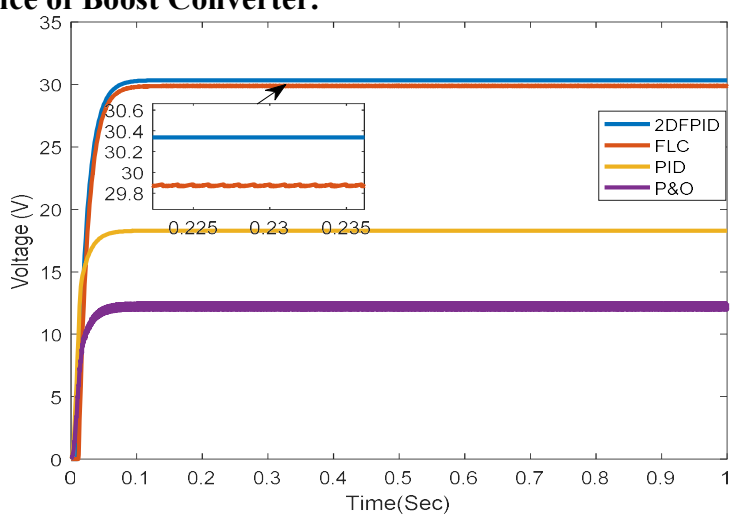

(b)

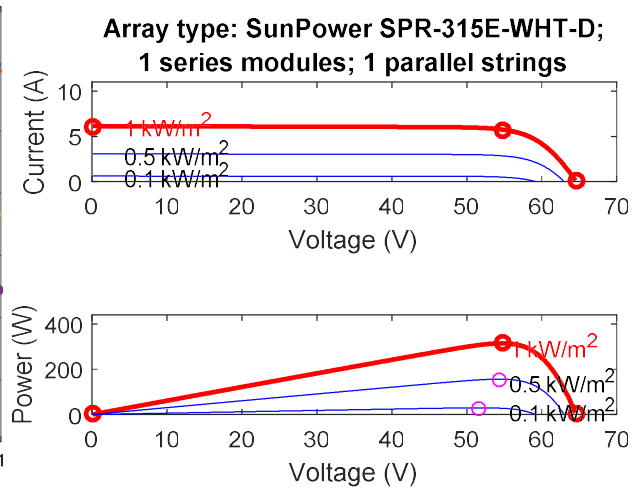

(d)

Fig. 5: (a) Power vs Time Graph (b) Voltage vs Time (c) Current vs Time Graph and (d) PV Module's I-V and P-V Characteristics

\section{Results and Discussion}

The optimal gain parameter of both PID and 2-DOF PID controllers is tuned by SCA algorithms with 25 repetitions with 100 populations. The objective of the algorithm is obtained with constraint as shown in equation (13)-(15).

$0.001 \leq K_{P}, K_{I}, \& K_{D} \leq 2$

$0 \leq P W \quad \& D W \leq 5$

$0 \leq N \leq 300$

Optimized values of PID and 2-DOF-PID controller are obtained by SCA is shown in Table 1. The comparison results of standalone PV system in terms of power, voltage and current shown in Fig. 5(a)-(c) respectively. Oscillation has been reduced using 2-DOF-PID which is clearly observed and also enhanced the output response of proposed PV system is shown in Fig. 5(a)-(c). PV module characteristic of I-V and P-V is depicted in Fig. 5 (d). The output response of DC- DC converter in terms of voltage, current and power is tabulated in Table 2. Implementation of 2-DOF-PID shows the better performance than fuzzy, PID and P\&O. 


\section{Conclusion}

The aim of this work is to enhanced the efficiency with minimize oscillation of PV system by implementing 2DOF-PID based MPPT technique. The 2-DOF-PID and PID controller is tuned gain parameter by SCA is validate better controller over the traditional and widely used $\mathrm{P} \& \mathrm{O}$ technique. Temperature, irradiance and load are the critical aspects which affect the current, voltage and power of the PV system. The 2-DOF-PID, FLC, PID, and P \& O based MPPT controller are performed by deviating the irradiance $\left(1000 \mathrm{~W} / \mathrm{m}^{2}\right.$ to 700 $\left.\mathrm{W} / \mathrm{m}^{2}\right)$ and with constant temperature $\left(25^{\circ} \mathrm{C}\right)$ and load $(5 \Omega)$. Reference voltage $\left(\mathrm{V}_{\text {ref }}\right)$ is calculated by the $\mathrm{P} \& \mathrm{O}$ based calculation algorithm. The output response of converter based on 2-DOF-PID controller is minimise the oscillation and enhanced the performance of PV system than other MPPT based controller as shown in Fig. 5(a)(c). The 2-DOF-PID is enhanced the performance and reduce the disturbance which is validated over the FLC, PID, and P\&O technique.

\section{References}

[1]. Esram T. and P. L. Chapman. 2007. Comparison of Photovoltaic Array Maximum Power Point Tracking Techniques. IEEE Trans. Energy Convers. 22: 2: 439-449.

[2]. Femia N., G. Petrone, G. Spagnuolo, and M. Vitelli. 2005. Optimization of perturb and observe maximum power point tracking method. IEEE Trans. Power Electron. 20: 4: 963-973.

[3]. Lian K. L., J. H. Jhang, and I. S. Tian. 2014. A maximum power point tracking method based on perturband-observe combined with particle swarm optimization. IEEE J. Photovoltaics. 4: 2: 626-633.

[4]. Killi Muralidhar and Susovon Samanta. 2015. Modified Perturb and Observe MPPT Algorithm for Drift Avoidance in Photovoltaic Systems. IEEE Trans. Industrial Electronics. 62: 9: 5549-5559.

[5]. Al-Diab, A., \& Sourkounis, C. 2010. Variable step size P\&O MPPT algorithm for PV systems. In 2010 12th International Conference on Optimization of Electrical and Electronic Equipment , IEEE. 1097-1102.

[6]. Salam Zainal, Jubaer Ahmed and Benny S. Merugu. 2013. The application of soft computing methods for MPPT of PV system : A technological and status review. Journal of Elsevier of Applied Energy.107: 135148.

[7]. Ishaque K. and Z. Salam. 2013. A review of maximum power point tracking techniques of PV system for uniform insolation and partial shading condition. Renew. Sustain. Energy Rev. 19: 475-488..

[8]. Reza A., M. Hassan, and S. Jamasb.2013. Classification and comparison of maximum power point tracking techniques for photovoltaic system: A review. Renew. Sustain. Energy Rev. 19: 433-443.

[9]. Kamarzaman N. A. and C. W. Tan. 2014. A comprehensive review of maximum power point tracking algorithms for photovoltaic systems. Renew. Sustain. Energy Rev. 37: 585-598.

[10]. Yang Y. R.. 2011. A Fuzzy Logic Controller for Maximum Power Point Tracking with 8-Bit Microcontroller. 5: 1078-1086.

[11]. Liu Y.H. Liu, C.L. Liu, J.W. Huang, and J.H. Chen. 2013. Neural-network-based maximum power point tracking methods for photovoltaic systems operating under fast changing environments. Sol. Energy, 89: 42-53.

[12]. Femia N., G. Petrone, G. Spagnuolo, and M. Vitelli. 2005. Optimization of Perturb and Observe Maximum Power Point Tracking Method. 20: 4: 963-973.

[13]. Shareef H., A. H. Mutlag, and A. Mohamed. 2015. A novel approach for fuzzy logic PV inverter controller optimization using lightning search algorithm,. Neuro computing, 168: 435-453.

[14]. Cheng P.C., B.R. Peng, Y.-H. Liu, Y.S. Cheng, and J.W. Huang.2015. Optimization of a Fuzzy-LogicControl-Based MPPT Algorithm Using the Particle Swarm Optimization Technique. Energies, 8: 6: 53385360 .

[15]. Oshaba A. S., E. S. Ali, and S. M. AbdElazim. 2017. PI controller design for MPPT of photovoltaic system supplying SRM via BAT search algorithm. Neural Comput. Appl., 28: 4: 651-667.

[16]. Nagarajan R., R. Yuvaraj, V. Hemalatha, S. Logapriya, A. Mekala, and S. Priyanga. 2017. Implementation of PV - Based Boost Converter Using PI Controller with PSO Algorithm. Int. J. Eng. Comput. Sci., 6: 3.

[17]. Zaghba, L., N. Terki, A. Borni, and A. Bouchakour.2015. Robust maximum power point tracking technique and PI current controller design for grid connected PV system using MATLAB/SIMULINK." Journal of Electrical Engineering 15: 315-320.

[18]. Neçaibia, A., Ladaci, S., Charef, A., \& Loiseau, J. J. 2015. Fractional order extremum seeking approach for maximum power point tracking of photovoltaic panels. Frontiers in Energy, 9: 1:43-53.

[19]. Sahu Rabindra Kumar, Sidhartha Panda, Umesh Kumar Rout, Dillip Kumar Sahoo. 2016. Teaching learning based optimization algorithm for automatic generation control of power system using 2-DOF PID controller, Elesevier journal of Electrical Power and Energy Systems , 77:287-301.

[20]. Mirjalili S.2016. SCA: A Sine Cosine Algorithm for solving optimization problems. Knowledge-Based Syst. , 96: 120-133. 